\title{
A High-Density Integrated Genetic Linkage and Radiation Hybrid Map of the Laboratory Rat
}

\author{
Robert G. Steen, ${ }^{1,8}$ Anne E. Kwitek-Black, ${ }^{2,8}$ Christopher Glenn, ${ }^{3,8}$ \\ Jo Gullings-Handley, ${ }^{2}$ William Van Etten, ${ }^{1}$ O. Scott Atkinson, ${ }^{2}$ Diane Appel, ${ }^{1}$
} Simon Twigger, ${ }^{2}$ Melanie Muir, ${ }^{1}$ Tim Mull, ${ }^{2}$ Mary Granados, ${ }^{2}$ Mushira Kissebah,, Kerri Russo, ${ }^{1}$ Robbin Crane, ${ }^{1}$ Michael Popp, ${ }^{3}$ Marc Peden, ${ }^{3}$ Tara Matise, ${ }^{4}$ Donna M. Brown, ${ }^{5}$ Jian Lu, ${ }^{2}$ Stephen Kingsmore, ${ }^{3}$ Peter J. Tonellato, ${ }^{2}$ Steve Rozen, ${ }^{1}$ Donna Slonim, ${ }^{1}$ Peter Young, ${ }^{1}$ Margit Knoblauch, ${ }^{6}$ Abraham Provoost, ${ }^{7}$ Detlev Ganten, ${ }^{6}$ Steven D. Colman, ${ }^{3}$ Jonathan Rothberg, ${ }^{3}$ Eric S. Lander, ${ }^{1}$ and Howard J. Jacob, ${ }^{2,9}$

${ }^{1}$ Center for Genome Research, Whitehead Institute for Biomedical Research and Massachusetts Institute of Technology, Cambridge, Massachusetts 02142 USA; ${ }^{2}$ Medical College of Wisconsin, Department of Physiology, Laboratory for Genetic Research, Milwaukee, Wisconsin 53226 USA; ${ }^{3}$ CuraGen Corporation, New Haven, Connecticut 06511 USA; ${ }^{4}$ The Rockefeller University, New York, New York 10021 USA; ${ }^{5}$ Research Genetics, Huntsville, Alabama 35801 USA; ${ }^{6}$ Max-Delbrück Center for Molecular Medicine, 13125 Berlin-Büch, Germany; ' Erasmus University, Department of Pediatric Surgery, Rotterdam, The Netherlands

\begin{abstract}
The laboratory rat (Rattus norvegicus) is a key animal model for biomedical research. However, the genetic infrastructure required for connecting phenotype and genotype in the rat is currently incomplete. Here, we report the construction and integration of two genomic maps: a dense genetic linkage map of the rat and the first radiation hybrid $(\mathrm{RH})$ map of the rat. The genetic map was constructed in two $\mathrm{F}_{2}$ intercrosses (SHRSP $\times$ BN and $\mathrm{FHH} \times \mathrm{ACl}$ ), containing a total of 4736 simple sequence length polymorphism (SSLP) markers. Allele sizes for 4328 of the genetic markers were characterized in 48 of the most commonly used inbred strains. The RH map is a lod $\geq 3$ framework map, including 983 SSLPs, thereby allowing integration with markers on various genetic maps and with markers mapped on the RH panel. Together, the maps provide an integrated reference to $>3000$ genes and ESTs and >8500 genetic markers (5211 of our SSLPs and >3500 SSLPs developed by other groups). [Bihoreau et al. (1997); ]ames and Tanigami, RHdb (http://www.ebi.ac.uk/RHdb/index.html); Wilder (http:/ / www.nih.gov/niams/scientific/ratgbase); Serikawa et al. (1992); RATMAP server (http:/ / ratmap.gen.gu. se)] RH maps (v. 2.0) have been posted on our web sites at http://goliath.ifrc.mcw.edu/LGR/index.html or http://curatools.curagen.com/ratmap. Both web sites provide an RH mapping server where investigators can localize their own RH vectors relative to this map. The raw data have been deposited in the RHdb database. Taken together, these maps provide the basic tools for rat genomics. The RH map provides the means to rapidly localize genetic markers, genes, and ESTs within the rat genome. These maps provide the basic tools for rat genomics. They will facilitate studies of multifactorial disease and functional genomics, allow construction of physical maps, and provide a scaffold for both directed and large-scale sequencing efforts and comparative genomics in this important experimental organism.
\end{abstract}

Defining the function of the $\sim 100,000$ mammalian genes is a major goal for biologists in the next century. The mouse is widely used for understanding gene function, owing to the availability of genetic and genomic infrastructure together with the ability to perform gene knockout and knockin studies. However, the mouse lags behind other species with respect to physiological characterization and does not correlate with human

\footnotetext{
${ }^{8}$ These authors contributed equally to this work. ${ }^{9}$ Corresponding author.

E-MAIL Jacob@mcw.edu; FAX (414) 456-6516.
}

clinical characteristics for a large number of diseases. The rat is arguably the most commonly used model for physiological studies. Accordingly, the rat is likely to have a key role in the interpretation of mammalian genomes.

Over the past century, the rat has been a key animal for biomedical research; since 1966 nearly 500,000 manuscripts using rats have been published [PubMed, National Center for Biotechnology Information (NCBI) search using "rat" as the key word (http://www.ncbi. nlm.nih.gov/PubMed/medline.html)]. The rat has served as a primary model in biochemistry, neurobiol- 
ogy, nutrition, pharmacology, physiology, and other fields. There are numerous genetic diseases and disorders identified in $>200$ inbred strains of rat (Greenhouse et al. 1990). These genetic models have been used extensively for the study of alcohol preference, autoimmunity, behavior, cancer, dental diseases, diabetes, eye disorders, hematological disorders, hypertension, metabolic disorders, neurobiology, renal failure, reproduction, skeletal disorders, and toxicology (Robinson 1965; Lindsey 1979; Gill et al. 1989). Given the wealth of biological and biomedical information, the rat has the potential to have a major role in functional genomics and pharmacogenetics, both through studies within the organism and through comparative genomics.

Over the past 3 years, there has been an explosion in the rat genetic and genomic infrastructure. Several large-insert genomic libraries (Cai et al. 1997; Haldi et al. 1997; Woon et al. 1998), which are key resources for physical mapping, positional cloning, and transgenesis, have been constructed. More than a dozen normalized cDNA libraries have been made (B. Soares, pers. comm.), from which $>90,000$ rat expressed sequence tags (ESTs; from dbEST, NCBI) have been sequenced. Nearly 10,000 genetic markers, primarily simple sequence length polymorphisms (SSLPs), have been developed by several groups [Serikawa et al. 1992; Jacob et al. 1995; Bihoreau et al. 1997; Brown et al. 1998; RATMAP server (http://ratmap.gen.gu.se); M. James and A. Tanigami, RHdb (http://www.ebi.ac.uk/ RHdb/index.html); R. Wilder, pers. comm. and http:// www.nih.gov/niams/scientific/ratgbase], although a minority have been mapped previously. A rat radiation hybrid (RH) panel has been generated, from which it is possible to develop an RH map that would allow a PCRbased method for localizing any sequence within the genome. A key limitation, however, has been the absence of a tool to enable investigators to integrate these reagents in a coordinated and efficient fashion.

To provide such a tool for genome-wide mapping and integration, we have created two integrated genomic maps: a dense genetic map and a RH framework map. This provides a level of genomic integration that was available only in the human and just now is becoming available for the mouse. The genetic and RH maps will serve as a backbone for (1) placing quantitative trait loci (QTLs) for disease models from different crosses onto a common map; (2) integration of ESTs onto a common map; and (3) comparative mapping between rat, human, and mouse.

\section{RESULTS}

\section{Genetic Linkage Maps}

In generating the first genetic linkage map of the rat, we determined that the average polymorphism rate between 12 inbred strains was 50\% (Jacob et al. 1995). Whereas mouse genetic maps can be constructed in interspecific crosses having a polymorphism rate of $90 \%$, no interspecific mapping crosses are available for the rat. Accordingly, we chose to generate genetic linkage maps from two different $\mathrm{F}_{2}$ intercrosses (SHRSP $\times$ BN and FHH $\times$ ACI) which enabled us to collectively map $>65 \%$ of all markers.

We mapped a total of 4736 SSLP markers, yielding a genetic map spanning $1477 \mathrm{cM}$ in the SHRSP $\times$ BN and $1527 \mathrm{cM}$ in the FHH $\times$ ACI (Kosambi map units). The average genetic length is $1503 \mathrm{cM}$ between the most distal markers, or $\sim 1515 \mathrm{cM}$ when allowing for the expected genetic distance beyond the most distal markers. The genetic length is remarkably close to the length calculated in our first genetic map in 1995 (Jacob et al. 1995), which consisted of 431 genetic markers (Table 1). However, the length is $>24 \%$ shorter than an integrated map, merging data from multiple published crosses, reported by Bihoreau et al. (1997). The increased length is likely the result of map expansion produced during the integration process. Some expansion was also seen in an integrated genetic map produced by our group (Brown et al. 1998).

As for the mouse (Dietrich et al. 1996) and human (Dib et al. 1996) genetic maps, the rat SSLP markers appear to be distributed in a relatively uniform fashion across the genome (Table 1), with two notable exceptions. There was a clear deficit of markers on chromosome $\mathrm{X}$, an observation that was reported previously for the rat (Jacob et al. 1995; Bihoreau et al. 1997; Brown et al. 1998) and for other mammalian species (Dib et al. 1996; Dietrich et al. 1996). There was also a significant excess of markers on chromosome 10, a trend which was observed (but fell below statistical significance) in our previous integrated map (Brown et al. 1998).

\section{Allele Characterization}

Use of the genetic markers in a given cross requires knowledge of polymorphism of markers between the strains. It would be impractical for an investigator to characterize all or most of the 5211 loci developed by our group. To facilitate the use of the markers and maps by a larger community, we determined the allele sizes for 4328 of our 5211 SSLPs in 48 of the most commonly studied inbred strains of the rat (Table 2). These 48 strains provide a total of 1128 pairwise combinations of crosses. These rat strains represent a large collection of disease models. A useful polymorphism was defined to be a difference $\geq 3 \mathrm{bp}$. The average rate of useful polymorphism between strains was $46 \%$, and the average number of alleles was determined to be 6 (range 2-16 alleles).

The allele data can also be used to generate haplotypes for use in comparing ancestral similarity between

\section{Genome Research}


Table 1. A Comparison of the Genetic Lengths of Various Maps

\begin{tabular}{|c|c|c|c|c|c|c|c|c|c|c|}
\hline \multirow[b]{2}{*}{ Chrom. } & \multirow{2}{*}{$\begin{array}{l}\text { Genetic } \\
\text { length } \\
\text { (avg.) }\end{array}$} & \multicolumn{2}{|c|}{ Percent of genome } & \multirow{2}{*}{$\begin{array}{l}\text { Observed } \\
\text { no. of } \\
\text { markers } \\
\text { (union) }\end{array}$} & \multirow{2}{*}{$\begin{array}{c}\text { Expected } \\
\text { no. of } \\
\text { markers }\end{array}$} & \multirow[b]{2}{*}{ S.D. } & \multirow[b]{2}{*}{ Z-score } & \multirow[b]{2}{*}{$\mathrm{SHR} \times \mathrm{BN}^{\mathrm{c}}$} & \multirow[b]{2}{*}{$\begin{array}{l}\text { Integrated } \\
\text { map }^{d}\end{array}$} & \multirow[b]{2}{*}{$\begin{array}{c}\text { Integrated } \\
\text { map }^{\mathbf{e}}\end{array}$} \\
\hline & & $\begin{array}{c}\text { genetic } \\
\text { map }^{a}\end{array}$ & $\begin{array}{l}\text { physical } \\
\text { map }^{b}\end{array}$ & & & & & & & \\
\hline 1 & 141.4 & 9.4 & 10.0 & 483 & 432 & 20.8 & 2.4 & 151.0 & 173.6 & 181.9 \\
\hline 2 & 110.6 & 7.4 & 8.9 & 379 & 385 & 19.6 & -0.3 & 157.0 & 133.8 & 144.8 \\
\hline 3 & 94.0 & 6.3 & 6.8 & 280 & 294 & 17.1 & -0.8 & 104.0 & 103.9 & 147.0 \\
\hline 4 & 104.2 & 6.9 & 6.6 & 282 & 285 & 16.9 & -0.2 & 105.0 & 102.3 & 154.4 \\
\hline 5 & 97.6 & 6.5 & 6.5 & 249 & 281 & 16.8 & -1.9 & 116.0 & 100.4 & 118.2 \\
\hline 6 & 72.8 & 4.8 & 5.6 & 221 & 242 & 15.6 & -1.4 & 76.0 & 77.7 & 83.7 \\
\hline 7 & 79.1 & 5.3 & 5.0 & 228 & 216 & 14.7 & 0.8 & 75.0 & 103.2 & 124.6 \\
\hline 8 & 83.8 & 5.6 & 4.7 & 227 & 203 & 14.3 & 1.7 & 97.0 & 86.5 & 112.9 \\
\hline 9 & 78.9 & 5.3 & 4.5 & 193 & 195 & 13.9 & -0.1 & 41.0 & 79.3 & 85.0 \\
\hline 10 & 92.9 & 6.2 & 4.3 & 262 & 186 & 13.6 & 5.6 & 94.0 & 98.9 & 62.1 \\
\hline 11 & 49.2 & 3.3 & 3.7 & 110 & 160 & 12.6 & -3.9 & 50.0 & 59.0 & 62.0 \\
\hline 12 & 43.1 & 2.9 & 2.5 & 112 & 108 & 10.4 & 0.4 & 54.0 & 47.8 & 55.7 \\
\hline 13 & 45.9 & 3.1 & 3.9 & 193 & 169 & 13.0 & 1.9 & 56.0 & 51.9 & 68.7 \\
\hline 14 & 68.8 & 4.6 & 3.9 & 143 & 169 & 13.0 & -2.0 & 43.0 & 55.2 & 79.7 \\
\hline 15 & 68.8 & 4.6 & 3.7 & 166 & 160 & 12.6 & 0.5 & 49.0 & 47.4 & 92.6 \\
\hline 16 & 45.9 & 3.1 & 3.4 & 127 & 147 & 12.1 & -1.6 & 17.0 & 23.2 & 56.1 \\
\hline 17 & 50.3 & 3.3 & 3.3 & 180 & 143 & 11.9 & 3.1 & 50.0 & 61.3 & 99.8 \\
\hline 18 & 52.3 & 3.5 & 3.2 & 147 & 138 & 11.8 & 0.7 & 44.0 & 53.9 & 85.0 \\
\hline 19 & 44.3 & 2.9 & 2.6 & 115 & 112 & 10.6 & 0.2 & 38.0 & 28.3 & 44.3 \\
\hline 20 & 36.7 & 2.4 & 2.2 & 77 & 95 & 9.8 & -1.9 & 47.0 & 54.5 & 56.5 \\
\hline$x$ & 42.0 & 2.8 & 5.4 & 149 & 233 & 15.3 & -5.5 & 45.0 & 35.9 & 83.2 \\
\hline Total & 1502.6 & 100.0 & 100.0 & 4323 & 4353 & 66.0 & -0.5 & 1509.0 & 1578.2 & 1998.2 \\
\hline \multicolumn{11}{|c|}{$\begin{array}{l}\text { a Jacob et al. (1995). } \\
\text { bebinson (1965). }\end{array}$} \\
\hline
\end{tabular}

strains. For this purpose, we declared a shared haplotype to be three or more consecutive markers within the same genetic bin $(\sim 1.3 \mathrm{cM})$ having the same allele size in two strains. Evaluation of a selection of haplotypes revealed that long-shared haplotypes ( $>10$ consecutive markers) were more prevalent in closely related strains known to be derived from the same progenitor. Also, as would be expected, strains with a higher polymorphism rate shared fewer haplotypes. These preliminary analyses suggest that shared haplotypes could be used to assess the ancestral relationships among the strains.

\section{RH Map}

RH mapping provides a powerful alternative means of mapping genes (Cox et al. 1990; Gyapay et al. 1996) without the need for first identifying a polymorphism. Based on our data, the rat RH cells retain an average of $25 \%$ of the rat genome, with a fragment size of $3.8 \mathrm{Mb}$. We omitted 12 of the 106 rat RH hybrids to conform to a 96-well format, including 6 hybrids with very low retention $(<0.5 \%)$ between hybrids $1-100$, as well as hybrids $101-106$.

Of an RH data set containing 5359 SSLP vectors, 983 were incorporated into a RH framework map for the rat (Fig. 1, poster). The framework map for each chromosome was constructed using the RHMAPPER computer program with loci ordered with an odds ratio of 1000:1 (lod score for order $\geq 3.0$ ). The framework map spans $19,368 \mathrm{cR}$, with $1 \mathrm{cR}_{3000}$ equaling $155 \mathrm{~kb}$. Figure 1 illustrates how the RH framework map correlates with the genetic maps. An initial comparison of the maps revealed that the $\mathrm{RH}$ maps for chromosomes 6, 10, and 13 did not have full telomeric representation. Review of the vectors for all markers on chromosomes 10 and 13 revealed very high retention of these regions in the RHs, higher than was acceptable according to our screening criteria (see Methods). The high retention of rat DNA for markers on chromosome 10 is likely due to the presence of the thymidine kinase gene, which is selected for in the generation of RHs; the reason underlying the high retention on chromosome 13 is unknown. The top three markers of chromosome 6 span the gap at the end of the chromosome. As an independent validation, the $\mathrm{RH}$ maps were evaluated using the MultiMap program. Although the two programs yielded slight differences in map length, the order of the loci was supported.

\section{Placement Maps}

We were able to place an additional 3876 markers, including SSLPs, genes, and ESTs relative to the RH 
Steen et al.

Table 2. Commonly Studied Rat Disease Models for which we Determined SSLP Allele Sizes

\begin{tabular}{|c|c|c|}
\hline Strain & Complete strain name & Disease model for \\
\hline $\mathrm{ACl}$ & $\mathrm{ACl}$ & spontaneous tumors, urogenital abnormalities, aplasia of one kidney \\
\hline AVN & AVN/Orl & immunology, autoimmunity \\
\hline $\mathrm{BB}(\mathrm{DR})$ & BBDR/WorAp Diabetic Resistant & diabetes resistant \\
\hline $\mathrm{BB}(\mathrm{DP})$ & BBDP/WorAp Diabetic Prone & diabetes (type 1) \\
\hline $\mathrm{BC} / \mathrm{CPBU}$ & $\mathrm{BC} / \mathrm{CpbU}$ & low frequency of audiogenic seizures \\
\hline BDIX & BDIX/Han & carcinogenesis, teratogenesis \\
\hline BDVII & BDVII/Cub & immunology \\
\hline$B N / C U B-L X$ & BN/Cub-Ix & blood pressure, cancer \\
\hline $\mathrm{BN} / \mathrm{SSN}$ & $\mathrm{BN} / \mathrm{SsNHsd}$ & blood pressure, cancer \\
\hline $\mathrm{BP}$ & $\mathrm{BP} / \mathrm{Cub}$ & cancer, immunology \\
\hline BUF & BUF/Pit & autoimmunity, cancer, drug abuse \\
\hline COP & COP/OlaHsd & cancer, immunology \\
\hline DA & DA/Pit & autoimmunity \\
\hline $\mathrm{FHH}$ & $\mathrm{FHH} /$ Eur & blood pressure, renal disease, bleeding diathesis \\
\hline $\mathrm{F} 344$ & F344/Pit & cancer, immunology, retinal degeneration in aged rats, drug abuse \\
\hline $\mathrm{GH}$ & $\mathrm{GH} / \mathrm{Omr}$ & blood pressure, cardiac hypertrophy \\
\hline GK & GK & diabetes (type II) \\
\hline DRY & Donryu/Melb & cancer, neoplastic lesions in 120 week old rats \\
\hline M520 & $\mathrm{M} 520 / \mathrm{N}$ & cancer, nephritis, immunology \\
\hline IS/Kyo & IS/Kyo & congenital malformations \\
\hline WN & WN/N & cancer, severe chronic nephritis \\
\hline $\mathrm{LH}$ & $\mathrm{LH}$ & blood pressure \\
\hline LE & LE/Mol & metabolic disorders \\
\hline LEW & LEW/Pit & autoimmunity, blood pressure, drug abuse \\
\hline $\mathrm{LOU} / \mathrm{C}$ & LOU/CHan & cancer \\
\hline LN & LN & blood pressure \\
\hline MHS & MHS/Gib & blood pressure \\
\hline MNR & $\mathrm{MNR} / \mathrm{N}$ & alcohol, stress \\
\hline MNRA & MNRA/Har & stress \\
\hline MNS & MNS/Gib & blood pressure, renal disease \\
\hline MR & MR/Pit & alcohol, stress, drug abuse \\
\hline NEDH & $\mathrm{NEDH} / \mathrm{K}$ & pheochromocytoma \\
\hline NP & NP9 & alcohol \\
\hline ODU & $\mathrm{ODU} / \mathrm{N}$ & dental disease \\
\hline OKA & OKA/Wsl & blood pressure \\
\hline OM & $\mathrm{OM} / \mathrm{Han}$ & cancer, obesity, retinal degeneration \\
\hline$P$ & P5C & alcohol \\
\hline PVG & PVG/Pit & autoimmunity \\
\hline SD & $\mathrm{SD} / \mathrm{Rij}$ & blood pressure, drug abuse \\
\hline SHR & SHR/OlaHsd & blood pressure \\
\hline $\mathrm{SR} / \mathrm{JR}$ & SR/Jrlpcv & blood pressure \\
\hline SHR-SP & SHRSP/Riv & blood pressure, stroke \\
\hline SS/JR & SS/JrMcw & blood pressure \\
\hline WAG & WAG/RijKyo & cancer \\
\hline WF & WF/Pit & cancer \\
\hline WIST & WIST/Nhg & cancer \\
\hline WKY & WKY/OlaHsd & blood pressure, drug abuse \\
\hline WTC & WTC/Kyo & congenital malformations \\
\hline
\end{tabular}

framework maps (data not shown). These vectors had a threshold lod $\geq 15$ for initial chromosome assignments and were placed with a lod $\geq 3$ relative to the framework maps. The data set used for placement contained all RH vectors (SSLPs, genes, and ESTs) regardless of the number of $2 \mathrm{~s}$ and $1 \mathrm{~s}$, and $0 \mathrm{~s}$. The remaining markers could not be uniquely placed according to these criteria.

\section{Comparison of Maps}

In total, 681 of the 983 framework markers on the RH map were also mapped in one or both genetic maps. These loci, shown in red in Figure 1, enable error checking of the order of the loci. There were 38 conflicts in order, and these were small differences in local order that likely reflect the uncertainties in the various maps.

\section{Integration of Other Maps}

The placement of $>4800$ markers onto a common $\mathrm{RH}$ map provides the ability to integrate the various genetic maps constructed to date, as well as providing a reagent to integrate future maps.

\section{DISCUSSION}

Over the past 4 years, rat genomics has progressed from

\section{Genome Research}


an initial genetic map of 431 genetic markers to the creation of an International Rat Genome Project. Although this effort has been quite successful, there has been limited effort to date to integrate the various reagents. Here, we report two integrated genomic maps: a dense genetic map, and the first RH map of the rat. Together, these maps provide basic infrastructure for rat genomics.

The total length of the genetic map is closer to $1500 \mathrm{cM}$ than the $2000 \mathrm{cM}$ estimated by several groups (Serikawa et al. 1992; Bihoreau et al. 1997). It is now clear that our initial genetic linkage map provided reasonably accurate estimates of the total genetic length and good coverage of the vast majority of the genome. However, efforts to integrate diverse maps from multiple groups, with limited numbers of markers in common, appear to have inflated the total genetic length (Table 1). The relationship between genetic distance and physical distance appears to be $\sim 1.9 \mathrm{Mb} / \mathrm{cM}$, assuming that the rat genome contains 3 billion base pairs.

The large number of markers (4328) for which allele sizes have been determined, together with software tools available on our web site, should assist investigators in selecting appropriate polymorphic markers to be used in particular crosses. For this purpose, polymorphic markers were defined as having allele size differences of at least $3 \mathrm{bp}$. (We used the standard of $\geq 3$ bp differences, rather than the minimum 2-bp differences between CA repeats, because the scoring of 2-bp differences among the 48 strains was less reliable.) It is important to note that many substrains of rat carry the same name. Consequently, allele sizes may not be identical in some strains with the same name. When possible, we have given the exact substrain used to generate these data (Table 2).

The availability of an RH map, integrated with a dense genetic map containing the most commonly used markers, is valuable for several reasons. First, these maps enable the integration of diverse genetic markers, including 5211 SSLPs developed by us, 2508 SSLPs developed at Otsuka Pharmaceutical Company (A. Tanigami, RHdb), 248 developed at Oxford (Bihoreau et al. 1997; M. James, RHdb), and 384 developed at the National Institutes of Health (NIH) (R. Wilder, pers. comm., http://www.nih.gov/niams/scientific/ ratgbase); this enables investigators to identify genetic markers in regions of interest without the need to characterize large numbers of markers in their particular cross. Second, the high-resolution map provides a starting point for developing a complete rat physical map, containing ordered large-insert clones spanning the genome. Finally, the RH map provides a means to rapidly localize any new locus, such as a gene, without the need to identify a polymorphism. Loci can be mapped simply by submitting the RH vector to a server on one of our web sites. This allows large-scale EST mapping, which facilitates positional cloning and comparative mapping (among different rat crosses and different species). Together with a group at the University of Iowa led by V. Sheffield and B. Soares, we are currently performing RH mapping on nearly 10,000 rat ESTs and genes.

The maps presented here provide a level of genomic integration that was available previously only in the human and just now is becoming available for the mouse. The genetic and RH maps serve as a backbone for the integration of ESTs and greatly facilitate comparative mapping among rat, human, and mouse. All of the basic genetic and genomic tools now exist that are needed to design approaches for determining and sequencing important regions of the rat genome containing QTLs for common human diseases. These tools allow biomedical researchers to maximally utilize the rat as a model system, as well as to link together rat, mouse, and human studies.

\section{METHODS}

\section{Generation of Simple Sequence Repeats}

Female rat genomic DNA (WKY) was digested with the restriction enzymes AluI, HaeIII, or RsaI (New England BioLabs). DNA digests were size-separated twice using 3\% NuSieve GTG agarose gels (FMC Bioproducts); two size fractions (250-450 and $450-700 \mathrm{bp}$ ) were collected. DNA was extracted and purified using the QIAquick gel extraction kit (Qiagen), cloned into M13mp18 (Pharmacia), transformed using XL-I Blue (Stratagene) or JM101 cells, and plated at a density of $\sim 250$ plaques per $110 \mathrm{~cm}^{2}$. Clones containing a simple sequence repeat (SSR) were identified by performing plaque hybridization and processed as described previously (Jacob et al. 1995). Libraries determined to contain phage with the majority of inserts in the 250- to 500-bp range were utilized to identify and characterize SSLPs.

DNA was isolated from the phage clones by automated solid-phase reversible immobilization assay (SPRI) (DeAngelis et al. 1995) and sequenced using ABI377 DNA sequencers (Applied Biosystems) with an automated version of the manufacturer's Taq cycle sequencing protocol. From the sequence, PCR primers flanking the SSRs were designed with Primer 3.0 (Rozen and Skaletsky 1996, 1997) to generate a product of $70-400 \mathrm{bp}$, with a $T_{\mathrm{m}}$ between $55^{\circ} \mathrm{C}-63^{\circ} \mathrm{C}$, devoid of apparent secondary structures, potential for primer-dimer formation, or repetitive elements (LINE, B1, B2, ID). In addition, sequence for each clone was screened against an internal database to avoid duplicate occurrences of the same locus. PCR primers were ordered from Research Genetics, Inc., and aliquots are available for purchase by the research community.

\section{Selection of Strains}

The SHRSP $\times \mathrm{BN} \mathrm{F}_{2}$ intercross (D. Ganten) was selected because of the rate of polymorphism and because it allowed integration with the German Rat Genome Project. The $\mathrm{FHH} \times \mathrm{ACI} \mathrm{F_{2 }}$ intercross (A. Provoost) was selected to increase the number of polymorphic markers on the two maps, because the parental strains were derived from progenitor strains different than SHRSP $\times$ BN. The 48 strains listed in 
Table 2 were selected because of their utility in studying a large number of common human diseases. Investigators interested in more details about these strains are encouraged to visit The Jackson Laboratories web site: http://www. informatics.jax.org/rat/. It should be noted that these are the official strain designations; names such as Brown Norway are no longer used (Levan et al. 1995).

\section{Construction of Genetic Linkage Maps}

Progeny from two independent $\mathrm{F}_{2}$ intercrosses (SHRSP $\times$ BN; 45 animals, or FHH $\times$ ACI, 46 animals) were genotyped by radiolabeled PCR reactions. The products were visualized by autoradiography following electrophoresis on polyacrylamide gels, as described previously (Dietrich et al. 1996). The following thermocycling protocol was used: initial denaturation at $92^{\circ} \mathrm{C}$ for $1 \mathrm{~min}$, followed by 35 cycles of $92^{\circ} \mathrm{C}$ for $30 \mathrm{sec}, 55^{\circ} \mathrm{C}$ for $30 \mathrm{sec}$, and $72^{\circ} \mathrm{C}$ for $30 \mathrm{sec}$, followed by a final extension period at $72^{\circ} \mathrm{C}$ for $5 \mathrm{~min}$. The presence of polymorphism was initially assayed by amplifying genomic DNA from the four inbred strains used for the two $\mathrm{F}_{2}$ intercrosses. Markers found to be polymorphic in one or both crosses were then amplified in the corresponding $\mathrm{F}_{2}$ intercross progeny.

Linkage analysis was performed by using the MAPMAKER computer program (Lander et al. 1987). Linkage assignment was confirmed by using a stringent lod threshold for linkage on each chromosome (lod > 5.0). Framework markers were ordered with a LOD threshold of 3.0. All other markers were placed in their most likely positions relative to this framework. Potential errors were detected by looking for double crossovers and using the MAPMAKER automatic error detection features (Lander et al. 1987). Marker order was compared between the two mapping crosses and the RH map. Discrepancies in marker order between the genetic and $\mathrm{RH}$ maps were checked by verifying the data on the original autoradiograph and corrected, if necessary.

The number of meioses- 90 for $\mathrm{F}_{2}($ SHRSP $\times \mathrm{BN})$ and 92 for $\mathrm{F}_{2}(\mathrm{FHH} \times \mathrm{ACI})$-allows markers to be resolved to an average resolution of $\sim 1.1 \mathrm{cM}$ in either cross. Total genetic length was calculated by measuring the intermarker distance for each chromosome (Table 1) and adding one-half the average intermarker distance $(0.3 \mathrm{cM})$ to each telomere. Orientation of the chromosomes is based on FISH analysis performed by Szpirer et al. (1998).

\section{Allele Characterization}

Allele sizes for 4328 of the markers were determined for the 48 strains using an internal size standard placed in every other lane. The gel marker (BioVentures, Murphreesboro, TN) was end-labeled using T4 ligase and $\left[\gamma_{-}{ }^{32} \mathrm{P}\right]$ ATP $(6000 / \mathrm{Ci}$ mmole). Genetic markers were characterized using essentially the same protocol as described above with the following modifications: Both primers were labeled, and the thermocycler program consisted of an initial denaturation at $93^{\circ} \mathrm{C}$ for $3 \mathrm{~min}$, followed by 35 cycles of $94^{\circ} \mathrm{C}$ for $30 \mathrm{sec}, 55^{\circ} \mathrm{C}$ for $30 \mathrm{sec}$, and $72^{\circ} \mathrm{C}$ for $30 \mathrm{sec}$, with a final extension period at $72^{\circ} \mathrm{C}$ for 3 $\min$.

The complete polymorphism information, primer names, and sequences are available at the web sites of the Whitehead Institute/MIT Center for Genome Research (http://www.genome.wi.mit.edu/rat/public/), the Medical College of Wisconsin (http://goliath.ifrc.mcw.edu/rat), and the Jackson Laboratories (http://www.informatics.jax.org/ $\mathrm{rat} /$ ).

\section{Construction of RH Map}

The rat RH panel was developed in the laboratory of Dr. Peter Goodfellow (L. McCarthy, Oxford University, UK; unpubl.). The panel was generated by using a cell line derived from a female Sprague Dawley rat that was exposed to 3000 rads, employing a protocol similar to that used in the generation of the GeneBridge 4 human radiation panel (Gyapay et al. 1996). DNAs to be used for mapping additional loci are available from Research Genetics Inc. (Huntsville, AL). To conform to both the 192- and 384-well format, we chose to use 94 of 106 hybrids for mapping, based on their retention frequencies, together with rat and hamster DNA controls. DNA from RH cell lines (20 ng) was PCR amplified in 10- $\mu$ l reactions containing 1.4 pmole of each primer, $250 \mu \mathrm{M}$ each dNTP, and 0.25 units of Taq polymerase. The PCR was performed using a Tetrad thermocycler in an oil-free system (MJ Research) with the following protocol: $3 \mathrm{~min}$ denaturing at $93^{\circ} \mathrm{C}$, and 35 cycles of $30 \mathrm{sec}$ at $94^{\circ} \mathrm{C}, 30 \mathrm{sec}$ at $48^{\circ} \mathrm{C}$, and $30 \mathrm{sec}$ at $72^{\circ} \mathrm{C}$, with a final 3 -min extension at $72^{\circ} \mathrm{C}$. Samples were mixed with loading dye and electrophoresed on $2 \%$ agarose gels $(1 \times$ TBE) containing $0.001 \%$ (vol/vol) GelStar nucleic acid gel stain (FMC) and imaged using the Eagle Eye still video system (Stratagene). The collective set of scores $(0=$ no amplification; $1=$ amplification; $2=$ uncertain) for a single marker is called an $\mathrm{RH}$ vector. All markers were assayed in duplicate to reduce errors (Lunetta et al. 1995), and a consensus was generated from the duplicate vectors; a score of 2 , in this case, indicates uncertain or discordant results.

Framework markers were selected by restrictive criteria. $\mathrm{RH}$ vectors with not more than four discrepancies between the duplicate vectors and neither too few $(<10)$ nor too many positives (>39) were used as framework markers. The same criteria were used when integrating into our data set 4494 genetic markers (1605 developed by our group) placed in RHdb, a public RH database at the European Bioinformatics Institute (http://www.ebi.ac.uk/RHdb/index.html). Where markers were assayed by more than one group, we used our $\mathrm{RH}$ vector when available, to enrich for markers assayed using a consistent protocol. The RH map data set contains 5359 vectors - 2537 were SSLPs developed by us for this work, 2508 were SSLPs developed by Otsuka Pharmaceutical Company (A. Tanigani, unpubl.), 248 were developed by Oxford University (Bihoreau et al. 1997; M. James, unpubl.), 58 were developed by NIH (R. Wilder, pers. comm., http:// www.nih.gov/niams/scientific/ratgbase), and 8 were developed by other groups (Table 3). Two exceptions were made to our criteria for framework markers. The q telomere of chromosome 10 and the $\mathrm{p}$ telomere of chromosome 13 contain markers with $>40$ 1s in order to extend the full chromosome length. All RH vectors, including SSLPs, genes, and ESTs, were used in the placement maps, with the duplicate markers serving as internal controls.

Whole-genome RH maps were constructed by using RHMAPPER and MultiMap computer programs (Matise et al. 1994; Stein et al. 1995). The framework map was constructed using RHMAPPER, initially without reference to the Whitehead genetic maps. Initially, the markers were separated by D number, and framework maps were built with an lod threshold for order of $\geq 3$. Marker order on the RH map was evaluated independently using the MultiMap program. For final error checking, the RH marker order was compared to the marker order in the genetic maps. The RH maps (v. 2.0) have been posted on our web site at http://goliath.ifrc.mcw.edu/ LGR/index.html or http://www.curatools.curagen.com/

\section{Genome Research}


Table 3. Source of SSLPs Listed by the Genetic or RH Maps

\begin{tabular}{|c|c|c|c|c|c|c|c|}
\hline $\begin{array}{l}\text { SSLP } \\
\text { type }\end{array}$ & $\begin{array}{c}\text { WIBR/MIT } \\
\text { CGR } \\
(\mathrm{SHRSP} \times \mathrm{BN})\end{array}$ & $\begin{array}{c}\text { WIBR/MIT } \\
\text { CGR } \\
(\mathrm{FHH} \times \mathrm{ACI})\end{array}$ & $\begin{array}{c}\text { WIBR/MIT } \\
\text { CGR } \\
\text { (Union of } \\
\text { two crosses) }\end{array}$ & Integrated $^{a}$ & $S H R \times B N^{b}$ & $\begin{array}{l}\text { Union of } \\
\text { all crosses }\end{array}$ & $\begin{array}{c}\text { RH } \\
\operatorname{map}^{c}\end{array}$ \\
\hline Rat & 3462 & 1836 & 4323 & 0 & 0 & 4323 & 2103 \\
\hline Mit/Mgh & 186 & 117 & 220 & 639 & 401 & 649 & 434 \\
\hline $\mathrm{Arb}^{\mathrm{d}}$ & 138 & 122 & 189 & 0 & 0 & 189 & 58 \\
\hline Got $^{\mathrm{e}}$ & & & & & & & 2508 \\
\hline Wox & & & & & & & 248 \\
\hline Other $^{f}$ & 4 & 1 & 4 & 38 & 30 & 50 & 8 \\
\hline Total & 3790 & 2076 & 4736 & 677 & 431 & 5211 & 5359 \\
\hline \multicolumn{8}{|c|}{$\begin{array}{l}\text { aBrown et al. (1998). } \\
\text { bJacob et al. (1995). } \\
\text { 'Includes both framework markers (Fig. 1) and placement markers (not shown in Fig. 1). } \\
\text { d'http://www.nih.gov/niams/scientific/ratgbase } \\
\text { ehttp://www.ebi.ac.uk/RHdb/index.html } \\
\text { fMarkers from GenBank and various other researchers. }\end{array}$} \\
\hline
\end{tabular}

ratmap. Both web sites provide an $\mathrm{RH}$ mapping server where investigators can localize their own $\mathrm{RH}$ vectors relative to this map. The raw data have also been deposited in the RHdb database.

\section{Marker Nomenclature}

Locus names for SSLPs are in accordance with the Rat Nomenclature Committee (Levan et al. 1995). For example, D1Rat1 refers to a locus on chromosome 1 isolated and mapped by the large-scale mapping project at the Whitehead Institute/ MIT Center for Genome Research and Medical College of Wisconsin. Other loci, such as RNO-D1Mit3, have the additional prefix RNO to denote $R$. norvegicus and, therefore, to avoid confusion with other loci developed by the same laboratory in other organisms (such as the mouse, human, or zebrafish). Fortunately, the Rat designation appears to be unique; therefore, RNO is currently not necessary for these loci. Markers with the symbol Mit are from the laboratory of E.S. Lander and coworkers at the Whitehead Institute/MIT Center for Genome Research; those with the symbol Mgh are from the laboratory of $\mathrm{H}$. Jacob et al. at the Massachusetts General Hospital; markers with the Mcw symbol are from the laboratory of $\mathrm{H}$. Jacob et al. at the Medical College of Wisconsin; markers with the symbol Arb are from the laboratory of R. Wilder, E. Remmers, and colleagues at the National Institute of Arthritis and Musculoskeletal and Skin Diseases; markers with the symbol Wox are from M. James and M. Lathrop at Oxford University; markers with the symbol Got are from A. Tanigami at Otsuka Pharmaceutical Company; markers representing gene sequence from GenBank utilize their GenBank gene name. For other previously published loci, we have used the designation given by the original authors, even when they do not necessarily conform to the standards established by the nomenclature committee (Levan et al. 1995).

\section{ACKNOWLEDGMENTS}

This work has been supported by National Institutes of Health grants HL55726 [National Heart, Lung, and Blood Institute (NHLBI)] to E.S.L. and H.J.J.; HL56284 and HL59826 (NHLBI) to H.J.J., and HG01691 and HG00008 (National Human Genome Research Institute) to T.M. This work has been accom- plished by a large group of people. Here we cite them and their contributions as suggested by Rennie et al. (1997) for manuscripts with large author lists.

Overall Project Leadership: Howard J. Jacob and Eric S. Lander.

Whitehead Institute for Biomedical Research: Project leader, Robert Steen; Genetic mapping, Diane Appel, Robbin Crane, Gail Farino, Vicki Frazzoni, Melanie Muir, and Kerri Russo; Informatics, William Van Etten (Team leader), Steve Rozen, Donna Slonim, and Peter Young.

Medical College of Wisconsin: Project leader, Anne E. Kwitek-Black; Allele characterization, O. Scott Atkinson (Team leader for first 2 years), Jo Gullings-Handley (Team leader for third year), Mary Granados, Rebecca Majewski, and Michelle Runte; RH mapping, Tim Mull (Team leader), Mary Granados, Jo Gullings-Handley, Moushira Kissebah, Rebecca Majewski, and Monika Stoll; Informatics, Peter J. Tonellato (Director), Jian Lu, and Simon Twigger.

CuraGen Corporation: Project leaders, Jonathan Rothberg and Steve Colman; RH mapping, Chris Glenn (team leader), Michael Popp, and Marc Peden.

Map Reanalysis: Tara Matise (Rockefeller University); Donna M. Brown (Research Genetics, Inc.).

Generation of SHRSP $\times \mathrm{BN} \mathrm{F}_{2}$ Intercross: Detlev Ganten (Director); Margit Knoblauch (Project leader).

$\mathrm{FHH} \times \mathrm{ACI} \mathrm{F}_{2}$ Intercross: Abraham Provoost (Director).

The publication costs of this article were defrayed in part by payment of page charges. This article must therefore be hereby marked "advertisement" in accordance with 18 USC section 1734 solely to indicate this fact.

\section{REFERENCES}

Bihoreau, M.T., D. Gauguier, N. Kato, G. Hyne, K. Lindpaintner, J.P. Rapp, M.R. James, and G.M. Lathrop. 1997. A linkage map of the rat genome derived from three $\mathrm{F}_{2}$ crosses. Genome Res. 7: 434-440.

Brown, D.M., T. Matise, G. Koike, J. Simon, E. Winer, S. Zangen, M. McLaughlin, M. Shiozawa, O. Atkinson, J. Hudson, Jr. et al. 1998. An integrated genetic linkage map of the laboratory rat. Mamm. Genome 9: 521-530.

Cai, L., L. Schalkwyk, A. Schoeberlein-Stehli, R. Zee, A. Smith, T. Haaf, M. Georges, H. Lehrach, and K. Lindpaintner. 1997. 
Steen et al.

Construction and characterization of a 10-genome equivalent yeast artificial chromosome library for the laboratory rat, Rattus norvegicus. Genomics 39: 385-392.

Cox, D.R., M. Burmeister, E.R. Priece, S. Kim, and R.M. Myers. 1990. Radiation hybrid mapping: A somatic cell genetic method for constructing high-resolution maps of mammalian chromosomes. Science 250: 245-250.

DeAngelis, M.M., D.G. Wang, and T.L. Hawkins. 1995. Solid-phase reversible immobilization for the isolation of PCR products. Nucleic Acids Res. 23: 4742-4743.

Dib, C., S. Faure, C. Fizames, D. Samson, N. Drouot, A. Vignal, P. Millasseau, S. Marc, J. Hazan, E. Seboun, M. et al. 1996. A comprehensive genetic map of the human genome based on 5,264 microsatellites. Nature 380: 152-154.

Dietrich, W.F., J. Miller, R. Steen, M.A. Merchant, D. Damron-Boles, Z. Husain, R. Dredge, M.J. Daly, K.A. Ingalls, T.J. O'Connor et al. 1996. A comprehensive genetic map of the mouse genome. Nature 380: 149-154.

Gill, T.R., G. Smith, R. Wissler, and H. Kunz. 1989. The rat as an experimental animal. Science 245: 269-276.

Greenhouse, D.D., M.F.W. Festing, S. Hasan, and A.L. Cohen. 1990. Catalog of inbred strains of rats. In Genetic monitoring of inbred strains of rats (ed. H.J. Hedrich), Gustav Fischer Verlag, Stuttgart, Germany.

Gyapay, G., K. Schmitt, C. Fizames, H. Jones, N. Vega-Czarny, D. Spillett, D. Muselet, J.F. Prud'Homme, C. Dib, C. Auffray et al. 1996. A radiation hybrid map of the human genome. Hum. Mol. Genet. 5: 339-346.

Haldi, M.L., P. Lim, K. Kaphingst, U. Akella, J. Whang, and E.S Lander. 1997. Construction of a large-insert yeast artificial chromosome library of the rat genome. Mamm. Genome 8: 284.

Jacob, H.J., D.M. Brown, R.K. Bunker, M.J. Daly, V.J. Dzau, A. Goodman, G. Koike, V. Kren, T. Kurtz, A. Lernmark et al. 1995. Genetic linkage map of the laboratory rat, Rattus norvegicus. Nat. Genet. 9: 63-69.

Lander, E.S., P. Green, J. Abrahamson, A. Barlow, M.J. Daly, S. Lincoln, and L. Newberg. 1987. MAPMAKER-An interactive computer package for constructing primary genetic linkage maps of experimental and natural populations. Genomics 1: 174 .

Levan, G., H.J. Hedrich, E.F. Remmers, T. Serikawa, and M.C. Yoshida. 1995. Standardized rat genetic nomenclature. Mamm. Genome 6: 447-448.

Lindsey, J.R. 1979. Historical foundations. In The laboratory rat (ed.
H.J. Baker, J.R. Lindsey, and S.H. Weisbroth), pp. 1-36. Academic Press, New York, NY.

Lunetta, K.L., M. Boehnke, K. Lange, and D.R. Cox. 1995. Experimental design and error detection for polyploid radiation hybrid mapping. Genome Res. 5: 151-163.

Matise, T., M. Perlin, and A. Chakravarti. 1994. Automated construction of genetic linkage maps using an expert system (multi-map): A human genome linkage map. Nat. Genet. 6: 384-390.

Rennie, D., V. Yank, and L. Emanuel. When authorship fails. 1997. A proposal to make contributors accountable. J. Am. Med. Assoc. 279: 22 .

RHdb, a public RH database at the European Bioinformatics Institute (http://www.ebi.ac.uk/RHdb/index.html). Web site contains data from Drs. Michael James and Akira Tanigami.

Robinson, R. 1965. Genetics of the Norway rat. Pergamon Press, Oxford, UK.

Rozen, S. and H.J. Skaletsky. 1996, 1997. Primer3. Code available at http://www-genome.wi.mit.edu/genome_software/other/ primer3.html.

Serikawa, T., T. Kuramoto, P. Hilbert, M. Mori, J. Yamada, C.J. Dubay, K. Linpaintner, D. Ganten, J.-L. Guenet, G.M. Lathrop, and J.S. Beckmann. 1992. Rat gene mapping using PCR-analyzed microsatellites. Genetics 131: 701-721.

Stein, L., L. Kruglyak, D. Slonim, and E. Lander. 1995. RHMAPPER, unpublished software, Whitehead Institute/MIT Center for Genome Research.

Szpirer, C., J. Szpirer, P. Van Vooren, F. Tissir, J.S. Simon, G. Koike, H.J. Jacob, E.S. Lander, K. Helou, K. Klinga-Levan et al. 1998. Gene-based anchoring of the rat genetic linkage and cytogenetic maps: New regional localizations, orientation of the linkage groups, and insights into mammalian chromosome evolution. Mamm. Genome 9: 721-734.

Woon, P.Y., K. Osoegawa, P.J. Kaisaki, B. Zhao, J.J. Catanes, D. Gauguier, R. Cox, E.R. Levy, G.M. Lathrop, A.P. Monaco, and P.J. de Jong. 1998. Construction and characterization of a 10-fold genome equivalent rat P1-derived artificial chromosome library. Genomics 50: $306-316$.

Received April 12, 1999; accepted in revised form April 27, 1999. Article published online ahead of print. See web site (www.genome.org) for date of publication.

\section{Genome Research}


Genome Research 9: AP1-AP8 (1999)

\section{A High-Density Integrated Genetic Linkage and Radiation Hybrid Map of the Laboratory Rat}

Robert G. Steen, Anne E. Kwitek-Black, Christopher Glenn, Jo Gullings-Handley, William Van Etten, O. Scott Atkinson, Diane Appel, Simon Twigger, Melanie Muir, Tim Mull, Mary Granados, Mushira Kissebah, Kerri Russo, Robbin Crane, Michael Popp, Marc Peden, Tara Matise, Donna M. Brown, Jian Lu, Stephen Kingsmore, Peter J. Tonellato, Steve Rozen, Donna Slonim, Peter Young, Margit Knoblauch, Abraham Provoost, Detlev Ganten, Steven D. Colman, Jonathan Rothberg, Eric S. Lander, and Howard J. Jacob.

L. McCarthy was mistakenly affiliated with Oxford University, UK in the above-mentioned paper. The correct affiliation should be Cambridge University, UK. 


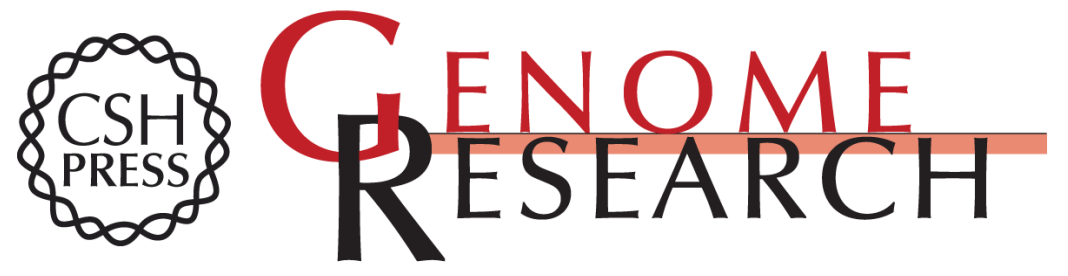

\section{A High-Density Integrated Genetic Linkage and Radiation Hybrid Map of the Laboratory Rat}

Robert G. Steen, Anne E. Kwitek-Black, Christopher Glenn, et al.

Genome Res. 1999 9: AP1-AP8

Access the most recent version at doi:10.1101/gr.9.6.AP1

Related Content Errata for vol. 9, p. 1AP

Genome Res. August, 1999 9: 793

License

Email Alerting Receive free email alerts when new articles cite this article - sign up in the box at the Service top right corner of the article or click here.

\section{Affordable, Accurate} Sequencing.

To subscribe to Genome Research go to:

https://genome.cshlp.org/subscriptions 